\title{
The Role of Zoos in Wildlife Conservation
}

\author{
By Peter Scott
}

In his keynote address to the Conference, Mr. Peter Scott, wearing, as he said, many hats-he is chairman of the World Wildlife Fund, the Survival Service Commission of the International Union for Conservation of Nature and the Fauna Preservation Societysurveyed the world scene of wildlife destruction and depletion, and the task of WWF. He listed six practical ways in which zoos might help in conservation, and suggested further that zoos could assist man to achieve a proper relationship with the natural world as well as to prevent further unnecessary extinction of species.

$\mathbf{O}^{\mathrm{N}}$ BEHALF of all the delegates to this Conference, I want to offer our congratulations to the San Diego Zoo on the 50th Anniversary of its Golden Jubilee. For this pleasant duty I find myself wearing no fewer than five hats. I offer congratulations and felicitations to the San Diego Zoo from the World Wildlife Fund, the International Union for Conservation of Nature, the Fauna Preservation Society, the Zoological Society of London, and the Wildfowl Trust. On behalf of all these I would like to salute the tremendous achievement of the San Diego Zoo. It really is an amazing 50 years' record of creative imagination in zoological science, in education, and in service to the community.

I speak as a zoo man, as well as a naturalist, because $I$ have been a Council Member of the London Zoo for the last twenty years, and because the collection of waterfowl which I founded down at Slimbridge is a sort of zoo. I am not an expert, but I do know enough about zoos to know what the achievement of the San Diego Zoo has been. We are sometimes envious of the San Diego climate, but, of course, it takes a good deal more than climate to make one of the greatest zoos in the world. To have called this conference is in itself an initiative of the highest importance. It demonstrates a considerable degree of far-sightedness and imagination on the part of the governing body of the San Diego Zoo. And it indicates a recognition of just how urgent this whole issue of conservation is all over the world.

There is a Portuguese proverb which says, "Architects cover their mistakes with creepers, cooks with sauces, doctors with earth." I have often had occasion to reflect ruefully that man covers the earth with his mistakes. Anyone who thinks ahead must be alarmed by the prospect for the human race. The biosphere is the bubble-thin layer of the earth's surface which supports life: it goes just as high as the California condors soar, just as high up the mountains as the lichens 
grow, just as deep into the oceans as the deep-sea echinoderms and the other bathyfauna can survive, and as deep into the earth as the tree roots grow and the ground squirrels dig. It is a terribly thin layer covering our earth, and it is finite. The human population increases, but the biosphere does not, and large parts of it already suffer from human over-population and extensive pollution of the atmosphere, the soil, the fresh waters and of the oceans. Population is the most causal of these problems, and we have got to solve it somehow; I personally have no doubt that we shall do so, because man is an extremely ingenious and successful animal. Science has discovered the means, and I cannot believe that man will not finally get this particular problem under control.

Meanwhile, until we solve it, until the flood of over-population finally recedes, we have to undertake a sort of "Noah's Ark" operation to tide us over. So the scope of the conservation task extends from over-population and pollution to species extinction, from the very broad issues of land use, of the welfare of humanity living in harmony with nature, of the interrelationship which makes up the science of ecology, at the one end, down to the specific requirements of individual species and sub-species which are the end product of 20 million centuries of evolution, and to particular communities of animals and plants which constitute a unique and irreplaceable heritage of mankind.

The Most Dangerous Predators

You may say that the extinction of species has been going on since the dawn of life; after all we have no dinosaurs with us today. But man, it seems, has accelerated the extinction rate of species in some animal groups by a factor of four. This has meant that more than one vertebrate animal form has become extinct per year during my lifetime. In the USA alone, eight kinds of fish are believed to have become extinct since the end of the second World War. What happened to the passenger pigeon and the Carolina parakeet is still happening in this day and age.

Many people say that man, the most dangerous predatory animal in the world, is just operating the laws of evolution, and this is no doubt true, but the point is that man is the first predator to realize what he is doing. He is the first one to feel shame. I think it was Mark Twain who said, "Man is the only animal that blushes or needs to."

Many people feel that what has happened to the species which have become extinct at the hands of 'civilised' and 'enlightened' man is in fact a disgrace to that same man; and let me remind those who say that we are merely operating the laws of evolution that this same evolution has evolved the conservationist. It has evolved the sort of thinking which has brought about this Conference; we are as much a product of evolution as the vandals or the destroyers. I think it 
would be right if $I$ were to suggest that most of us in this room now sincerely believe that we should, if we possibly can, leave a place in the sun for all the animal and plant species that share this world with us.

Today, at least a thousand vertebrate forms are threatened with extinction. You will hear a large number of different figures for threatened species; they refer to areas, to particular groups of animals, and, of course, also to the degree of threat; how threatened is threatened? We believe that it is important to record the threat to a species earlier rather than later, because if in fact it is not so seriously threatened no great harm is done, but if it proves to be rarer than we thought, it may become extinct while we are not looking.

\section{The Red Data Book}

The Survival Service Commission of the International Union for Conservation of Nature has published a Red Data Book of Endangered Species. There are 210 mammals in Volume 1, and 259 birds in Volume 2 , and we are currently working on a reptile and amphibian volume, a fish volume, and an invertebrate animal volume. A plant volume will come later. The Red Book is a loose-leaf book and each species or sub-species has a page: pink when the threat to the species is acute, and green when the threat has been removed. Obviously the intention is to make the entire book one of green pages. The white pages are for species that are not so seriously threatened but are not considered safe, and there are more white pages than any others. This is a loose-leaf book because the headquarters of the Survival Service Commission in Morges, Switzerland, is maintaining a continuous investigation into the situation facing these species and is sending out fresh sheets as new information becomes a vailable. About twice a year all holders of the Red Book get fresh sheets as replacements for some of the existing sheets, bringing the whole volume up to date. The cost of these two volumes is $\$ 25.00$, which includes the service that keeps them up to date for a period of five years.

\section{The Action Treatment}

Of course, when we finally get all these facts into a book, this is only stage one of the operation. Stage two is called "the action treatment." We have a list of steps which can be taken to save species from extinction, ranging from the purchase of land for a national park or the establishment of a research project, down to the adoption of a conference resolution or the promotion of a pictorial postage stamp of the animal in question. There are something like thirty different items on the list, and we are trying to consider the appropriateness of these items for every species in the red book. With over a thousand threatened vertebrate animals the job is going to take some time to complete. 
THE

CONFERENCE

SPEAKERS

Right: Peter Scott Chairman

Below: Richard Fitter Perez M. Olindo

Photos: San Diego Zoo

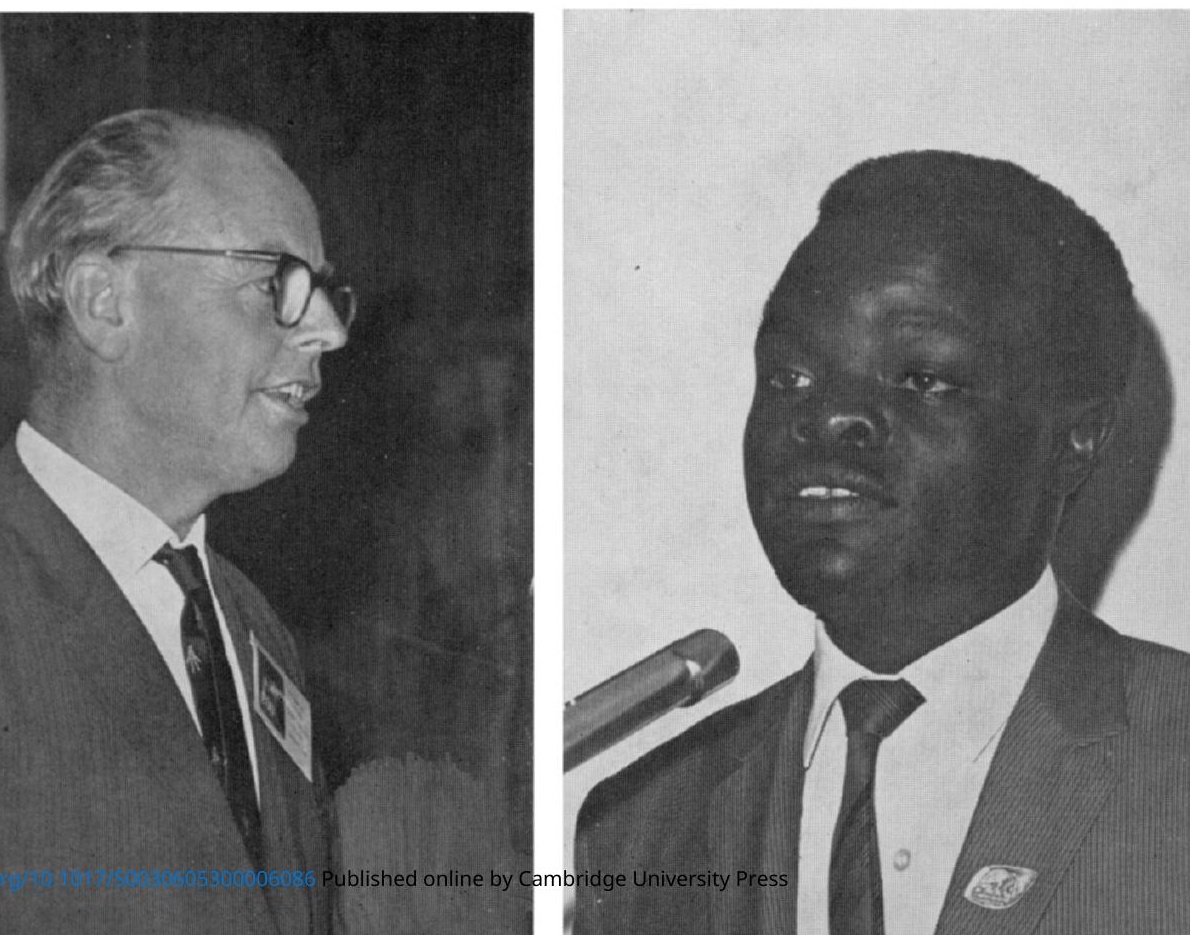


CONFERENCE

SPEAKERS

\section{Left: Ian Crimwood}

Below: Charles E. Shaw

Dr Eric Guiler

Opposite above:

Miss Caroline Jarvis

Dr Lee M. Talbot

Below: Dr F. Carlos Lehmann

Dr Boonsong Lekagul

Photos: San Diego Zoo 
Meanwhile, the 'community chest' for the world conservation movement is the World Wildlife Fund, an international charitable foundation which operates from headquarters in Switzerland and has national appeals in a number of different countries. WWF (US) is an entirely independent organisation, which it must be in order to qualify for tax deductibility. Our aim is to raise $\$ 6$ million a year all over the world, which incidentally is half the cost of a jet bomber, or one twelfth the cost of an ocean liner, or the cost of three or four world-famous paintings-not much to pay for the survival of so much that is unique and irreplaceable. We take great pains to preserve the world's works or art in our galleries; it seems strange that we are not prepared to put down a little money to preserve the works of God-the beauty and wonder of nature that inspire all mankind.

\section{Where the Zoos come in}

This is WWF's Noah's Ark operation. How do the zoos fit into this pattern? I would like to suggest that there are six ways in which the zoos can be helpful. First, of course, is education--education in natural history and the principles of ecology on which must be based the whole future of conservation itself. The second is the general increase of aesthetic appreciation of animals. This is important because people are much more receptive to the idea of conservation if they have a genuinely warm feeling for wild animals. The third is the study of threatened species: there is a great deal still to be learned about them and, more and more, zoos are making a scientific programme an integral part of their work; nowhere is that more true than here in San Diego. The fourth is the actual breeding of threatened species thereby increasing the population. Only a day or two ago I saw the rare Arabian oryx in the Phoenix Zoo where they are being successfully bred, and here in San Diego I have seen the results of the splendid breeding programme of Galapagos tortoises. Many other animals in San Diego are extremely rare and should be bred in captivity if this can be done. This may involve the translocation of individual animals, and I am most anxious that the Survival Service Commission and the zoos should collaborate in setting up a translocation unit capable of moving animals all over the world, and using when necessary the most up to date techniques including properly tested tranquillisers and narcotic drugs to catch the animals and move them to areas where they can be bred. Such methods would particularly apply to the now extremely rare tamarau, the small wild cattle of the Philippines, and I hope very much that something may be done to rescue this species. I hope the San Diego Zoo will help with this because they have specialists who are knowledgeable about this group of animals. They have the right climate here and $I$ hope they will be able to find the time and space to undertake an operation of this kind.

My fifth suggestion for ways in which zoos can help is in fund raising. We have invited many zoos to set up wishing wells, which 
collect quite small sums of money but it is surprising how they mount up. In a small place like the Wildfowl Trust, the wishing well raises nearly $\$ 2,000$ a year in pennies and sixpences and half-crowns; moreover, this does not cut down the amount that is spent in our shop or in the restaurant. Another fund-collecting method is the WWF model giant panda, with a cub, which has a little crack in the top of its head into which coins can be put. These models stand about 3 feet high and if properly sited they raise something like $\$ 150.00$ a year each. Soon we hope in England to have 5,000 of them in the streets.

The sixth way in which zoos may be able to help is by maintaining an acute sense of their responsibility in the matter of exhibiting rare species and by taking great care not to acquire single animals which therefore have no prospect of breeding in captivity. In this connection, I greatly hope that we may be able to go forward with the quota system which I proposed two years ago. This would operate on an international scientific assessment of the status and reproduction rate of rare and threatened species in the wild, with an estimate of what numbers could with safety be taken into captivity each year. In some cases the quota might have to be nil for a considerable time, but in the end it should be possible to allow small numbers to go to zoos. Captured animals would only be distributed to zoos with proven records of breeding success with the animal in question or some close relative.

Some people say that no very rare animals should be allowed into zoos. I am totally opposed to that view. It is essential that people should be allowed to see animals, and especially rare animals, if they are to be concerned for their survival and to support world conservation. Furthermore captive breeding can be a real safeguard for a species. When you think of the species which, say ten years ago, had never been bred in captivity, you realise the immense progress which zoos have made in the care of their animals. Those who now breed these animals have quite clearly demonstrated that in the long run it will be possible to breed almost any animal under good captive conditions.

I hope I have adequately indicated that conservation for the long term benefit of all mankind is something which concerns us all. It is in the main stream of human progress. The world's zoos have a great part to play in many different ways towards the achievement of a proper relationship between man and the natural world around him, and an important role, too, on the technical side, in preventing the further unnecessary extinction of animal species. 